\title{
POR UMA ABORDAGEM EXPERIENCIALISTA DO DIREITO: A METAFORICIDADE DA COGNIÇÃO E AS REALIDADES JURÍDICAS
}

\author{
Monica Fontenelle Carneiro* \\ Rodrigo Dutra da Silva**
}

\section{Resumo:}

O presente estudo objetiva apresentar o direito e a prática jurídica como categorias cognitivas e linguísticas expressas metaforicamente, bem como a importância da metáfora para a capacidade humana de pensar e construir sentidos. Para tanto, utiliza-se de metodologia qualitativa mediante a abordagem da Teoria da Metáfora Conceptual de George Lakoff e Mark Johnson, apresentada na obra "Metáforas da Vida Cotidiana" (1980[2002]), tudo com amparo em instrumentais bibliográficos, notadamente literatura nacional e estrangeira. Os resultados alcançados indicam que a retórica jurídica é estruturada metaforicamente para ocultar seu caráter, expressando uma pretensa objetividade, mas que o discurso emergente é interacional e negociado.

Palavras-chave: direito; prática jurídica; sentidos; cognição; metáforas.

\section{ABSTRACT BY AN EXPERIENTIAL APPROACH TO THE LAW: THE METAPHORICITY OF COGNITION AND LEGAL REALITIES}

\begin{abstract}
:
This study aims to present law and legal practice as cognitive and linguistic categories metaphorically expressed, as well as the importance of metaphor for the human capacity of thinking and building up meanings. For this reason, a qualitative methodology is used by means of George Lakoff and Mark Johnson's Conceptual Metaphor, presented in the work "Metaphors We Live By" (1980[2002]), supported by bibliographical instruments, notably national and foreign literature. The results achieved indicate that legal rhetoric is metaphorically structured to conceal its rhetorical character, expressing a supposed objectivity, but that the emerging discourse is interactional and negotiated.
\end{abstract}

Keywords: law; legal practice; meanings; cognition; metaphors.

\section{CONSIDERAÇÕES INTRODUTÓRIAS}

O presente estudo tem a finalidade de, à luz da Teoria da Metáfora Conceptual de George Lakoff e Mark Johnson, constante na obra "Metáforas da Vida Cotidiana" (1980[2002]), apresentar a experiência jurídica como orientada decisivamente por categorias cognitivas e linguísticas expressas metaforicamente.

\footnotetext{
* Doutora e Mestra em Linguística pela Universidade Federal do Ceará (UFC). Professora dos Programas de PósGraduação em Letras (Mestrado Acadêmico) da Universidade Federal do Maranhão (UFMA) em São Luís e Bacabal. Professora colaboradora do Programa de Pós-Graduação em Direito da UFMA. E-mail: <monicafcarneiro@gmail.com>.

** Discente do Mestrado em Direito e Instituições do Sistema de Justiça da Universidade Federal do Maranhão (UFMA). Bacharel em Direito pela Universidade Estadual do Maranhão (UEMA). E-mail: <rodrigodutrasilva@hotmail.com>.
} 
Nesse diapasão, entende-se que a suposta literalidade arrogada historicamente pelo raciocínio jurídico é fruto de uma retórica objetivista que depositou no discurso da cientificidade moderna a confiança na possibilidade de um conhecimento verdadeiro, despido dos preconceitos da coletividade e do próprio pesquisador, mas que, em verdade, a metáfora é um instrumento da cognição subjacente até mesmo a tais raciocínios.

Considera-se, portanto, que os discursos jurídicos são construídos metaforicamente porque o próprio fenômeno jurídico é assim compreendido, possibilitando uma leitura crítica da retórica em torno da objetividade que inspira a ciência do direito.

O intento se justifica pela aptidão que possui de acrescentar ao estudo jurídico, ainda que introdutoriamente, as noções de metaforicidade, retórica e poética tradicionalmente ocultadas da linguagem do direito, permitindo uma releitura crítica dessa circunstância e uma posição científica mais atual, realista e responsável por parte do próprio pesquisador da ciência jurídica.

Com efeito, pretende-se apresentar as digressões filosóficas modernas sobre cientificidade, literalidade e objetividade, além de suas repercussões no âmbito da linguística e do direito, a fim de, em seguida, compreender a estruturação do pensamento humano mediante o paradigma da linguística cognitiva, à luz da Teoria da Metáfora Conceptual de Lakoff e Johnson (1980 [2002]), de modo a subsidiar uma análise do caráter metafórico do pensamento jurídico e de sua necessária abordagem por meio de uma perspectiva experiencialista.

Trata-se de pesquisa de metodologia qualitativa e de caráter exploratório que, por meio das categorias de abordagem propostas pela Teoria da Metáfora Conceptual de George Lakoff e Mark Johnson, expressas na obra "Metáforas da Vida Cotidiana" (1980[2002]), pretende responder às indagações supramencionadas, tudo com amparo em instrumentais bibliográficos, especialmente literatura especializada nacional e estrangeira.

\section{A ABORDAGEM ESTÁTICA DA LINGUAGEM, DA COGNIÇÃO E DO DIREITO}

A ambição de compreender o modo humano de apreender conhecimento e expressálo sempre norteou os intentos filosóficos da cultura ocidental. A cognição, que é basicamente relacionada ao processamento de informações experimentadas pelas pessoas, tornou-se objeto de epistemologia própria, por conseguinte. 
Todas as explicações acumuladas ao longo dos séculos sobre o assunto construíram uma densa tradição que se enraiza nas culturas comuns e especializadas, dentre as quais a referente ao direito e instituições de justiça.

As pesquisas acerca da linguagem, tradicionalmente, afirmam ser esta um módulo específico da cognição mais geral. Conforme definições clássicas de Noam Chomsky, autor da teoria da Gramática Gerativa, o módulo cognitivo da linguagem tem a exata função de descrever, por meio de expressões linguísticas ou sentenças, aquilo que é real no mundo concreto (FERRARI, 2018, p. 13-15). Portanto, o significado linguístico é reputado um reflexo da realidade, relacionando-se diretamente ao objeto descrito.

A oportunidade de se analisar as expressões linguísticas sob essa perspectiva permite que se valore as sentenças respectivas como verdadeiras ou falsas, numa estrutura de raciocínio formalista da linguagem e da síntaxe.

Ocorre que, em verdade, as bases do pensamento de Noam Chomsky representam o desdobramento lógico de uma retórica que norteou todo o pensamento ocidental ao longo dos séculos e foi reforçado desde a modernidade, a saber, o racionalismo, segundo o qual a definição precede a compreensão com base em um modelo estático.

A ideia de que haja uma existência concreta no mundo, verdadeira, e uma percepção concomitante por parte do sujeito observador, puramente pessoal e passível de equívocos, insere firmemente na tradição filosófica o dualismo entre objetivismo e subjetivismo.

A maneira objetiva de entender as coisas é reputada formalista e se ampara numa pretensão de verdade decorrente do inatismo. Não sem razão, a retórica cartesiana, símbolo máximo da aludida tradição filosófica, apresenta viés universalista que se expressa por meio de sentenças de caráter quase metafísico e próprias do espectro semiótico das digressões respectivas, tais como "racionalidade", "cientificidade" e "verdade", quase como sinônimas. O que "não é racional, ou que não se justifica racionalmente, é tratado como arbitrário" (PARINI, 2013, p. 82-83).

Assim, a ciência, como meio de compreensão racional das coisas objetivas do mundo, exige do pesquisador um comprometimento com a objetividade, consoante a mentalidade moderna, sendo o propósito de universalização e de busca de critérios mínimos inerente à própria concepção de epistemologia. 
Todo o esforço de compreensão objetiva do mundo é parte de outro muito bem intencionado de tornar a mentalidade científica despida de preconceitos que limitem injustificadamente a essencial postura curiosa e crítica do pesquisador.

O objetivismo, como tradição filosófica, apresenta-se como a resposta a demandas por integridade, igualdade/constância e justiça, em busca da suposta verdade (razão) por trás do objeto de estudo, portanto.

No âmbito da linguística, expressa-se o aludido pensamento por meio da divisão conceitual entre sentido literal e metafórico das palavras ou sentenças. Opõem-se, assim, literalidade e metaforicidade. O conhecimento científico, uma vez comprometido com a objetividade, apega-se à noção de literalidade, por evidente. Busca-se retirar do debate da ciência, conseguintemente, toda e qualquer expressão de caráter figurativo ou performático.

Literalizar o conhecimento, nesse sentido, representa a forma por meio da qual, mediante estabilizações de sentido, a ciência moderna pretendeu precisar conteúdos, afastar dispersões e prevenir o equívoco.

Assim ocorre porque a objetivação de um campo discursivo tem a efetiva aptidão de gerar confianças no uso de linguagens que, a priori, seriam dotadas de instabilidade, permitindo uma compreensão lógica e autorreferencial de fenômenos etiologicamente dispersos. A ciência necessita dessa estabilização para cumprir seu papel e se utiliza, para tanto, exatamente dos recursos que a linguagem oferece.

A ciência do direito, em especial, consolidou-se adotando a perspectiva alhures descrita ao abandonar ao máximo o viés subjetivista e metafórico, de modo a abraçar a literalidade, a formalidade, a objetividade e a pretensão de verdade enquanto efetivas exigências das demandas de justiça, igualdade e sistematicidade que lhes são subjacentes.

Assim, a ciência do direito e a atividade do jurista buscaram, sistematicamente, afastar-se do metafórico, sob o argumento de que a metáfora era serviente apenas a deturpar ou ludibriar o conhecimento (PARINI, 2014, p. 27-32), com o fim de supostamente imunizar o saber verdadeiro do equívoco e do engano.

O processo de objetivação da linguagem jurídica, portanto, representou uma tentativa geral de dar coerência universal e neutralidade ao produto da investigação dos juristas no âmbito da ciência, o que se promoveu mediante critérios de literalização e por categorizações de ordem estruturante. 
Com efeito, a formatação do pensamento jurídico se organizou deliberadamente de maneira modular, adotando perspectivas dessa índole, tais como "ramos do direito", "sistema jurídico" ou categorizações peremptórias, a exemplo de dualismos como "lícito" e "ilícito" ou "válido" e "inválido".

Outro instrumento de estabilização foi a colocação das recursividades jurídicas em termos literais pelo uso de enunciados normativos escritos. Parini (2015, p. 16) observa que exatamente "a ideia de escrever o direito, isto é, literalizá-lo ou, propriamente, transformá-lo em letra, seria um modo de torná-lo mais sofisticado ou refinado do ponto de vista de sua racionalidade e inteligibilidade".

A criação de recursos próprios a serem seguidos de modo autorreferencial dotou o trabalho dos juristas de unidade de sentido, desvinculando-o de questões que, apriorísticamente, teriam maior carga de moralidade ou mesmo de teor político. Objetivar, portanto, visou também imunizar socialmente o espectro jurídico para atender expectativas sociais de segurança acerca das próprias instituições judiciárias.

Ao reduzir a complexidade das premissas do trabalho jurídico a aspectos objetivos, a ciência jurídica diminuiu enormemente os encargos argumentativos e filosóficos a que se submetem os juristas, criou constâncias e reforçou as expectativas sociais de confiança historicamente situadas.

Conforme Ferraz Júnior (2003, p. 34), tal esforço de redução cognitiva, enquanto pressuposto de qualquer sistematização eficaz, é essencial à atividade prática do jurista, tendo em vista que, segundo o autor, uma "complexidade não reduzida a aspectos uniformes e nucleares gera angústia, parece subtrair-nos o domínio sobre o objeto".

Assim, não se pode descuidar do papel histórico da retórica objetivista em favor da emancipação do conhecimento científico em relação às demais formas de saber humanas, num esforço geral de diferenciação que permitiu o amadurecimento da compreensão ocidental acerca da cientificidade e de seus limites.

Por outro lado, todo o esforço acima descrito denota que o objetivismo não possui a pretensa neutralidade que arroga insistentemente. Em verdade, a construção de sentidos reputados objetivos, por possuir pretensão autorrealizadora, simplesmente oculta determinadas leituras sobre as coisas do mundo em favor de outras. Por isso, o objetivismo moderno é insuficiente para responder adequadamente às demandas atuais de justificação e à reflexibilidade do conhecimento. 


\section{A LINGUÍSTICA COGNITIVA E AS METÁFORAS ESTRUTURAIS}

A atitude filosófica anteriormente descrita não foi imune de críticas ao longo do tempo por razões que decorrem da maturação da compreensão acerca da própria linguagem, a qual representa o principal recurso a dispor do cientista para explanar seus raciocínios.

No âmbito dos estudos linguísticos, desenvolveu-se um paradigma teórico que se pôs em oposição às visões tradicionais de Noam Chomsky, chamado "Linguística Cognitiva", a ser explicado sucintamente adiante.

A Linguística Cognitiva defende que a capacidade de compreensão humana não é modular, mas única e obediente a princípios cognitivos partilhados. Nesse sentido, os mecanismos de aprendizagem motora são os mesmos utilizados para aprendizado linguístico, por exemplo, de sorte a retirar do estudo da linguística a suposição de que a experiência sensório-motora e a sociocultural seriam periféricas ao aprendizado.

A teoria afirma que a cognição humana, em geral, é orientada pela vivência e pelas experiências corpóreo-sensoriais pré-conceptuais das pessoas, de modo que a "natureza peculiar de nosso[s] corpos modela nossas possibilidades de conceptualização e categorização" (FERRARI, 2003, p. 28), em geral inconscientes.

As palavras, portanto, expressam não a literalidade, mas noções que podem ser puramente contextuais. A relação entre palavra e mundo é mediada pela cognição, sendo fruto de uma construção baseada na experiência. Assim, sentenças possuem sentidos, mas não contém significados peremptórios (FERRARI, 2018, p. 14), de forma que a dualidade entre literalidade e metaforicidade passou a ser mais criticamente analisada.

Tradicionalmente, a suposição de que todas as palavras possuem um sentido próprio e podem eventualmente possuir um sentido figurado foi prevalente. $\mathrm{O}$ sentido verdadeiro seria certo e o figurado, eventual. Por essa razão, a metáfora, consistente na utilização de palavras fora de seus sentidos literais, seria simplesmente um ornamento retórico excepcionalmente utilizado, especialmente pelo seu suposto potencial de produzir engano (COSTA; CARVALHO, 2017, p. 108).

A leitura ortodoxa entende as metáforas, portanto, como "representações parciais ou deturpadas da realidade em questão, contentando-se com uma semelhança aproximativa" (OLIVEIRA, 2014, 1159), motivo pelo qual seriam essas úteis apenas para situações em que 
fosse necessário expressar ideias difíceis, complexas, densas ou subjetivas com simplicidade, como estratégia comunicativa.

As discussões cognitivistas, entretanto, colocaram em dúvidas os citados pressupostos, especialmente após a apresentação dos trabalhos de George Lakoff e Mark Johnson sobre o papel das metáforas na construção do pensamento e, consequentemente, da linguagem do dia a dia.

É que, segundo defendem, a "metáfora está infiltrada na vida cotidiana, não somente na linguagem, mas também no pensamento e na ação" (LAKOFF; JOHNSON, 2002, p. 45). A tese é de que é realmente impossível compreender o mundo apenas em bases literais. Por isso, constantemente as pessoas interpretam as coisas em termos de outras, ou seja, compreendem metaforicamente.

A compreensão metafórica dar-se-ia quase que automaticamente e de maneira imperceptível na mente humana, evidenciando-se apenas mediante a linguagem (LAKOFF; JOHNSON, 2002, p. 45-48). A metáfora é prévia às expressões linguísticas por meio das quais são transmitidas, portanto.

Por isso, pode-se dizer que, enquanto estruturas cognitivas, as noções metafóricas surgem no pensamento, não na linguagem, de sorte que a metáfora passa a ser entendida como uma necessidade discursiva, onipresente e necessária. Como explica Schmitte (2017, p. 25):

\footnotetext{
Lakoff e Johnson não estão interessados em metáforas impressionantes, retóricas ou literárias, mas naquelas da linguagem habitual. Essas metáforas cotidianas não são tomadas como expressões idiomáticas individuais, mas como provas de estruturas cognitivas comuns ("cognitivo", para Lakoff e Johnson, inclui fenômenos sensoriais, emocionais, culturais e de ação). A tais padrões comuns de transmissão de significados dá-se o nome de "conceitos metafóricos".
}

As metáforas que servem tanto para auxiliar a compreensão do mundo quanto para estruturá-lo são chamadas de "metáforas conceptuais estruturais". Por meio dessas, os conceitos são "estruturados metaforicamente em termos de outros", de modo que "um conceito mais estruturado possa integrar outro" (COSTA; CARVALHO, 2017, p. 110).

Assim ocorre porque, quando as pessoas não conseguem descrever certas coisas que lhes parecem demasiadamente abstratas, recorrem ao conhecimento experiencial (gestalts) acumulado relativo a outros raciocínios já estruturados, chamados de "domínios", por serem mais concretos e aptos à comparação. 
Conforme o exposto, conclui-se, com apoio na Teoria das Metáforas Conceptuais de George Lakoff e Mark Johnson (1980[2002]), que o processo de metaforização não é puramente restrito à poética ou à retórica, entendimento prevalente desde os gregos, mas representa uma genuína construção cognitiva geral. Em verdade, as metáforas são conceptuais, permitindo a formação de ideias pela organização da experiência em termos estruturais, ontológicos e orientacionais.

Para compreensão da estruturação da recursividade metafórica, deve-se entender previamente que existem dois domínios experienciais observáveis, um fonte e outro alvo, sendo o primeiro projetado, em alguns de seus traços, no segundo. Basicamente, a "estrutura do domínio-fonte precisa ser preservada pela projeção, de modo consistente com o domínioalvo" (FERRARI, 2018, p. 97). Conforme observa Ferrari (2018, p. 92):

\footnotetext{
A metáfora é, essencialmente, um mecanismo que envolve a conceptualização de um domínio de experiência em termos de outro. Sendo assim, para cada metáfora, é possível identificar um domínio-fonte e um domínio-alvo. O domínio-fonte envolve propriedades físicas e áreas relativamente concretas da experiência, enquanto o domínio-alvo tende a ser mais abstrato.
}

A utilização de um domínio para definir outro exige compatibilidades que, não raro, dependem de conhecimentos contextuais por parte de quem raciocina e, ulteriormente, daquele a quem se comunica, o que demonstra o caráter conceptual da metáfora.

Em todo caso, reitera-se que as recursividades metafóricas caracterizam o domínioalvo apenas parcialmente, tendo em vista que a metáfora tanto esclarece quanto oculta, especialmente quando implica aspectos muito específicos.

A compatibilidade entre domínios é fruto do processo de categorização, ou seja, do processo por meio do qual as pessoas agrupam "entidades semelhantes (objetos, pessoas, lugares etc.) em classes específicas" (FERRARI, 2018, p. 31). Trata-se, em tese, de uma igualação arbitrária de elementos desiguais, sendo ignoradas particularidades, o que, contudo, na prática, representa tarefa fundamental para a estruturação do pensamento humano.

Entende-se que as metáforas conceptuais, para serem bem comprendidas, expressamse através de um esquema básico e unidirecional segundo o qual X É/SÃO Y. Um exemplo do exposto são as metáforas TEMPO É ESPAÇO e TEMPO É MOVIMENTO, as quais permitem que se expresse a abstração do tempo como algo que voa, passa ou para. Outro exemplo é a metáfora do conduto, segundo a qual IDEIAS SÃO OBJETOS, PALAVRAS 
SÃO RECIPIENTES e COMUNICAÇÃO É ENVIO, consubstanciada em sentenças como “o argumento dado a ele não tem conteúdo”. A metáfora DISCUSSÃO É GUERRA permite que se entenda a discussão como algo belicoso, no qual os combatentes tomam posições, recuam, atacam e podem sofrer perdas, enquanto a metáfora DISCUSSÃO É VIAGEM permite apreender a discussão como um caminho a ser percorrido, com ou sem percalços, desvios, rapidez e etc.

Por seu inerente potencial engenhoso, as várias metáforas conceptuais podem interagir criando sistemas metafóricos mais complexos (redes de significação), com recursividades que exigem maior experiência do interlocutor para o devido entendimento, tendo caráter contextual.

Por exemplo, ao se dizer que TEMPO É DINHEIRO, pode-se conferir ao tempo qualquer qualidade atribuível ao dinheiro decorrente de outras implicações metafóricas, de sorte que, compreendendo-se que DINHEIRO É PODER, infere-se que TEMPO É PODER, o que não afasta compreensões outras mais intuitivas como a de que o tempo pode ser gasto, investido, valioso ou desperdiçado, a partir da análise do contexto e da realidade dos intelocutores concretos.

Outro exemplo é DIREITO É JUSTIÇA, metáfora por meio da qual se reforça cotidianamente a expectativa de que as instâncias jurídicas correspondam a determinados valores sociais. Assim, atrubui-se a tudo o que se considera direito, como a lei ou a decisão judicial, a necessidade de correspondência a valores metaforicamente aliados à concepção de justiça, tais como igualdade, liberdade ou utilidade.

Portanto, as pessoas entendem as coisas do mundo por meio de implicações entre categorias de metáforas diversas que interagem entre si, demonstrando e ocultando aspectos do fenômeno alvo, de modo que as "implicações metafóricas podem caracterizar um sistema coerente de conceitos metafóricos e um sistema coerente de expressões metafóricas correspondente a esses conceitos" (LAKOFF; JOHNSON, 2002, p. 52).

Uma metáfora sistemática é, então, um padrão de conceptualização resultante de um conjunto de metáforas conectadas numa ambiência recursiva muitas vezes difusa e não necessariamente comprometida com ideais metafísicos de verdade. São essas estruturações que inerentemente orientam o raciocínio e a linguagem humanas a partir dos dados da experiência, uma vez que são frutos de representações que emergem da interação entre 
participantes, efetivamente situados no espaço e no tempo, conforme o discurso evolui (CARNEIRO, 2014, p. 115-116).

Considerando o exposto, a Teoria da Metáfora defende que são as metáforas convencionais que estruturam nosso sistema conceptual ordinário e suas abstrações mais acentuadas (PARINI, 2015, p. 14).

Os conceitos metafóricos sistemáticos repercutem e orientam as ações humanas, ampliando ou restringindo experiências. Assim, são abertos e dotados de imenso potencial ao engenho humano, razão pela qual "há espaço no interior dessas restrições gerais para extensa variação cultural no modo pelo qual o significado é entendido e elaborado" (FERRARI, 2003, p. 26).

Por isso, afirma-se que a "atividade interpretativa está diretamente ligada ao caráter social da cognição e do sujeito, que age construindo uma identidade e conhecimentos por meio da interação e da projeção entre domínios" (SOUSA, 2007, p. 19).

A noção de literalidade, em verdade, teria efetivamente a ver com a estabilização de sentidos metafóricos, revelando um grau consolidado de utilizações a ponto de se considerar o dado inerente ou extremamente aproximado ao espectro empírico.

Logo, tem-se que o próprio "processo metafórico cria uma ilusão de correspondência entre a linguagem e o mundo" (PARINI, 2015, p. 19), pois simplesmente "não há qualquer fronteira firme o suficiente capaz de demarcar completamente o sentido literal e diferenciá-lo de todos os demais" (PARINI, 2015, p. 18).

Assim, orientando adequadamente a percepção dos fenômenos do mundo social, pode-se compreender com realismo, crítica e atualidade a emergência dos discursos objetivistas e da retórica literalizante que ampara as noções modernas de cientificidade, inspiradoras da ciência jurídica, a partir da percepção de potenciais e limites.

\section{A METAFORICIDADE DO DIREITO}

Se a metáfora é mecanismo de cognição e pensamento, conclui-se que as pessoas, sem metáfora, em vários domínios seriam incapazes de se expressar ou sequer pensar (PARINI, 2015, p. 14). No âmbito do conhecimento jurídico, isso acentua-se pelo caráter abstrato das ideias a serem categorizadas e expressas, eis que dotadas de notável grau de dispersão e fragmentariedade. 
Assim, a própria literalidade a que se apega a ciência jurídica é metafórica, denotando uma estratégia do discurso jurídico que objetiva persuadir mediante a transmissão de imparcialidade, distanciamento e justiça própria da concepção de objetividade moderna.

A literalidade, enquanto metáfora ontológica que é, nas palavras de Vereza (2007, p. 117), promove “a ilusão de que podemos identificar, classificar e modificar as 'coisas do homem' da mesma forma que abordamos as "coisas do mundo"'. A concepção literal, abstrata, é entificada ou coisificada de modo a ser apreendida como coisa concreta, ontologicamente.

Assim, "o sentido literal pode ser conceituado, de uma maneira geral, como uma metáfora ontológica que entifica o sentido, para que, intermediado pela 'sabedoria poética', o homem, com sua linguagem, possa refletir e agir sobre esse sentido" (VEREZZA, 2007, p. $118)$.

A heurística do direito e a prática jurídica são, na realidade, baseadas em dados experienciais extremamente difusos, de inerente complexidade. A especialização a que passa o direito é, então, um instrumento metafórico que visa estabilizar sentidos mediante expressões técnicas e categorizações de precisão vocabular.

Muitas dessas recursividades são polissêmicas e somente podem ser bem compreendidas contextualmente, importa dizer, sendo partes de um esquema mental de assimilação mediante redução de complexidades, mas aberto. Em todo caso, a necessária coerência conceitual decorre da necessidade retórica de asseverar a objetividade que se visa transmitir (CASTRO JÚNIOR, 2019, p. 13).

Disso resulta a compreensão metaforizada do direito enquanto sistema lógico, formal, estético, dedutivo e dotado de plenitude, o que justifica a constante busca do jurista por ontologias em que se possa amparar ${ }^{1}$. Diante da suposta naturalidade do sistema, uma interpretação etiológica aparentemente imparcial da realidade fragmentária justifica-se ao menos para que se possa persuadir que assim ocorre ${ }^{2}$. A profecia da sistematicidade, simbolicamente, então, torna-se autorrealizadora.

\footnotetext{
${ }^{1}$ Nesse sentido, importa diferenciar a ontologia proposta no parágrafo, posta no sentido de "essência", das chamadas metáforas ontológicas, por meio das quais se entende que "nossa experiência com objetos físicos e substâncias nos fornece uma forte base conceitual para a compreensão de outros aspectos da experiência não necessariamente provenientes do mundo físico" (VEREZA, Solange Coelho. Literalmente falando: sentido literal e metáfora na metalinguagem. Niterói: EdUFF, 2007, p. 116).

${ }^{2} \mathrm{O}$ que não se dá aleatoriamente, senão mediante a crença de que um "modelo autêntico de racionalidade só poderia ser alcançado em uma ontologia que lhe seja própria, isto é, que corresponda a sua forma de ser ou de
} 
Ou seja, através do processo de categorização das realidades jurídicas, mediante a criação de conceitos metafóricos epistêmicos, manipulam-se circunstâncias como se estas essas fossem parte de um todo ordenado, donde decorre a crença sistêmica do direito, a qual, em si, é uma corporificação da própria noção abstrata de "direito" ou "jurídico".

Agrupam-se deliberadamente elementos racionais, intuitivos e imaginativos, mesclando as retóricas das ontologias (demonstrabilidades) e deontologias (arbitrariedades), de sorte a se elaborar um modelo que permita uma abordagem dedutiva do fenômeno. Assim, constroem-se os conceitos jurídicos, que nada mais representam que crenças compartilhadas entre partes de um campo discursivo específico em relação à linguagem dita comum (OLIVEIRA, 2014).

Com efeito, "a formalização da linguagem jurídica é um modo de metaforização da própria linguagem do direito" (PARINI, 2015, p. 26). Tal processo se justifica funcionalmente, ou melhor, instrumentalmente, eis que muitos dos conceitos de direito são como que alegorias didáticas, com finalidades descritivas e epistêmicas, ou são pressupostos de análise que orientam a percepção abstrata de relações de causa e efeito pretendidas e naturalizadas na realidade jurídica. Logo, a "univocidade e o significado literal na teoria dogmática do direito são, portanto, operacionalmente fundamentais, mas não lhe pertencem" (PARINI, 2013, p. 107).

Assim, entende-se que, quando o pensamento jurídico ocidental buscou se desvencilhar da retórica e da poética, em verdade, instrumentalizou-se contraditoriamente exatamente por meio de uma retórica que visava ocultar seu próprio caráter, induzindo aquilo que seriam pressupostas implicações de naturalidade, ou seja, etiologias.

Não sem razão, a teoria do direito se utiliza, por um lado, de "modelos descritivos de uma realidade que é ou que existe", e, de outro lado, de "modelos prescritivos que procuram impor ao jurista prático uma metodologia de abordagem dos problemas jurídicos a partir de uma realidade que deve ser" (PARINI, 2013, p. 82).

A retórica jurídica se utiliza de uma "metáfora para encobrir outra, fazendo assim esta última parecer uma literalidade, um conceito denotativo científico" (CASTRO JÚNIOR, 2019, p. 19). Contudo, apesar da negação da retórica promovida na realidade jurídica, todo discurso é retórico, inclusive o jurídico.

existir" (PARINI, Pedro. A retórica da metáfora dos modelos na teoria do direito. Seqüiência, n. 67, p. 81-110, dez. 2013, p. 88). 
Por isso, Parini observa que, longe de serem literais, "os enunciados teóricos da 'ciência' jurídica revelam mais a capacidade criativa e intuitiva do teórico do que propriamente uma relação de correspondência com as diversas realidades do direito" (PARINI, 2013, p. 83).

Disso decorre a necessidade de uma abordagem do fenômeno jurídico numa perspectiva que assuma seu caráter amplo e criativo, o que pode se dar a partir da leitura experiencialista própria da Teoria da Metáfora em Lakoff e Johnson.

A retórica objetivista, muitas vezes reducionista, centra atenções no mundo externo, nas coisas que existem independentemente dos sujeitos, de modo a orientá-los a serem bem sucedidos nos ambientes cultural e físico, bem como manifesta preocupações com igualdade, imparcialidade e justiça (LAKOFF; JOHNSON, 2002, p. 343-344). Contudo, baseia-se na ideia de verdade cartesianamente verificada, o que é um equívoco, pois não "há como distinguir exatamente o que é inato do que é aprendido" (FERRARI, 2003, p. 25).

Por isso, o objetivismo, malgrado ser decorrente de intenções hígidas, alimentou mitos que embaraçaram o desenvolvimento científico, especialmente a ilusão de que exista a possibilidade de se alcançar a neutralidade do investigador perante aquilo que se busca conhecer (MINAYO, 2016, p. 23).

A ideia de neutralidade científica, em geral, decorre de um raciocínio estruturado para distinguir sujeito e objeto cognoscível, de sorte a colocá-los em compartimentos estanques e incomunicáveis, numa perspectiva modular. O equívoco do qual decorre o mito da neutralidade, portanto, é estrutural.

É que inexiste como predeterminar se a influência primeira à cognição humana é ambiental ou subjetiva, o que é inato e aprendido. Assim, mais prudente é reconhecer que a capacidade humana de aprender deriva, em verdade, da constante interação entre sujeito e objeto cognoscível construído, numa perspectiva de reciprocidade ou mesmo de simbiose (MARQUES NETO, 2001).

Nesse sentido, a compreensão humana deve ser entendida como amparada num sistema não universal de conceptualização das coisas do mundo, razão pela qual a objetividade deve ser revista, especialmente se se considerar a razoável hipótese de tensões entre sistemas conceptuais conflitantes.

As "evidências das ciências cognitivas demonstram que não há uma faculdade autônoma da razão separada e independente das capacidades corporais tal como percepção e 
movimento", mas "indicam que a razão se desenvolve-se a partir dessas capacidades corporais" (FERRARI, 2003, p. 27). Assim, abrem-se caminhos para um exercício responsável e realista da linguagem, da interpretação e da argumentação presentes na ciência jurídica, bem como nas ciências em geral.

Por outro lado, a pura interpretação subjetivista, sempre relativista, tão repelida pela ciência positivista do direito, por igual não merece recepção. É que o subjetivismo aponta acertadamente a não predeterminação do sentido das coisas (não literalidade), mas seu caráter imaginativo individual e não condicionado é inadequado.

As propriedades interacionais do sujeito com o mundo e suas experiências de fato são importantes para a construção de sentidos, de modo que a crença subjetivista de que a potencialidade imaginativa humana é irrestrita se apresenta ingênua demais para ser tomada com seriedade (LAKOFF; JOHNSON, 2002, p. 345-346).

A cognição humana dá-se interacionalmente e expressa-se por meio de metáforas que são frutos do processo por meio do qual o sujeito interage constantemente com o ambiente, o que redunda em transformações mútuas, trocas e concessões O processo cognitivo é flexível e interativo, portanto.

Assim, os sentidos são produtos de uma constante negociação estruturada pelas categorias das experiências humanas que constroem a compreensão e a autocompreensão, numa perspectiva efetivamente construtivista.

As leituras centradas no objetivismo e reducionismo, bem como no subjetivismo e relativismo, demonstram-se inconsistentes com a realidade, pois representam extremos intuitivos ou lógicos, mas que não precisamente se identificam concretamente. Há uma efetiva necessidade de que o pensamento jurídico questione mais detidamente tais tradições filosóficas para que possa lograr desenvolvimento.

A visão experiencialista "encara a experiência como resultado de estruturas cognitivas e sensório-motoras corporificadas que geram significado através de interações permanentes com ambientes em constante mudança” (FERRARI, 2003, p. 25), o que permite valorar o direito como realidade social e linguística.

O 'significado não provém, portanto, apenas de estruturas 'internas' ao organismo, nem tampouco de estruturas 'externas', mas sim de padrões recorrentes de interação entre organismo e ambiente" (FERRARI, 2003, p. 25). 
Com efeito, o Direito não se permite compreender conceitualmente sem lacunas gritantes, em sua dinamicidade e engenhosidade, senão por meio da criativa e adaptativa metaforicidade inerente ao pensamento humano.

É esta metaforicidade que, se bem compreendida, permite que se tome em consideração criticamente os padrões e recursividades contruídos pela ciência jurídica ao longo dos últimos séculos, tais como refinamentos de entendimento, estabilizações de sentido e procedimentos que se integram ao caráter da vida social contemporânea, sendo de fundamental relevo à compreensão fenomênica do Direito pelo jurista.

\section{CONSIDERAÇÕES FINAIS}

As teorias do conhecimento e da linguagem modernas baseiam-se em perspectivas estáticas e formalistas de interpretação da capacidade humana de pensar e exteriorizar ideias e raciocínios. Tratam-se de abordagens com pretensão de confiabilidade e certeza que se amparam numa retórica objetivista do saber científico para fins persuasivos.

O conhecimento jurídico assimilou tal entendimento e, desde então, teve desenvolvimento dogmático orientado a ressaltar a primazia da objetividade e da literalidade, em oposição ao subjetivismo supostamente decorrente das alegorias metafóricas, pautando-se em formas de negação à retórica e à poética.

Contudo, a cognição humana, exteriorizada pela linguagem, não é modular, sendo, em verdade, grande parte dos conceitos humanos decorrentes de raciocínios metafóricos que licenciam expressões linguísticas.

Ou seja, compreende-se que é, por meio de metáforas conceptuais que não são meramente estilísticas, que as pessoas são capazes de dar concretude a ideias abstratas difíceis de definir sem tal recurso, inclusive aquelas dotadas de cientificidade no discurso corrente, exteriorizando-as por meio da linguagem com diferentes graus de precisão vocabular.

Em verdade, a suposição de que a metaforicidade representa uma alegoria abstrata do pensamento que conduz ao engano e à imprecisão decorre de um preconceito acentuado na cultura ocidental ao longo de séculos de tradição filosófica. Mediante tal preconceito, reforçou-se a confiança em torno da retórica cientificista moderna, em oposição ao discurso secular, ocultando seu inerente caráter retórico.

Disso decorre a necessidade de se abordar o fenômeno jurídico, invariavelmente fragmentário, a partir de uma leitura experiencialista e à luz da metaforicidade. É que o 
próprio direito, heuristicamente, e a experiência jurídica não se podem interpretar em termos conceituais estritos, senão com o auxílio criativo e flexível que as metáforas conceptuais já acrescem ao pensamento dos juristas imperceptivelmente.

Todas as categorias metafóricas são implicações de sentido ou recursividades limitadas a determinados espectros dos domínios envolvidos, de sorte que tanto ocultam quanto esclarecem, o que denota sua adequação à abordagem do fenômeno jurídico como realidade social e discursiva.

Assim, por meio de uma leitura experiencialista, permite-se a abertura de caminhos para uma abordagem pluralista, cientificamente responsável, prudente e realista dos fenômenos categorizados como próprios da realidade jurídica.

\section{REFERÊNCIAS BIBLIOGRÁFICAS}

CASTRO JÚNIOR, Torquato da Silva. O olho e o retrato: aspectos metafóricos da teoria do fato jurídico. R. Jur. FA7, v. 16, n. 2, p. 13-27, jul/dez 2019.

CAMERON, L. et al. The discourse dynamics approach to metaphor and metaphorled discourse analysis. Metaphor and Symbol, Philadelphia, v. 24, n. 2, p. 63 - 89, 2009.

CAMERON, L.; MASLEN, R. Metaphor analysis: research practice in applied linguistics social sciences and humanities. Sheffield: Equinox Publishing, 2010.

CARNEIRO, Monica Fontenelle. Emergência de Metáforas Sistemáticas na Fala de Mulheres Vítimas Diretas de Violência Doméstica: uma análise cognitivo-discursiva. 425 f. Tese (Doutorado em Linguística) - Programa de Pós-Graduação em Linguística, Universidade Federal do Ceará, Fortaleza, 2014.

CHIAVEGATTO, Valeria Coelho. Introdução à linguística cognitiva. Revista Matraga, v. 16, n. 24, p. 77-96, jan/jun 2009.

COSTA, Gisele de Araújo; CARVALHO, João Claudio Carneiro de. As metáforas estruturais no discurso do Supremo Tribunal Federal: uma análise pitanêutica da construção do signo "reincidência". Revista Ciências Humanas e Sociais, Facipe, vol. 3, n. 1, p. 105-122, jul. 2017.

FERRARI, Lilian. A linguística cognitiva e o realismo corporificado: implicações filosóficas e psicológicas. Revista de Estudos Linguísticos, Juiz de Fora, vol. 5, n. 2, p. 23-29, jul./dez. 2003. 
FERRARI, Lilian. Introdução à linguística cognitiva. 1. ed. 3. reimp. São Paulo: Contexto, 2018 .

FERRAZ JÚNIOR, Tércio Sampaio. Introdução ao estudo do direito: técnica, decisão, dominação. 4. ed. São Paulo: Atlas, 2003.

LAKOFF, George; JOHNSON, Mark. Metáforas da vida cotidiana. Tradução: Maria Sophia Zanotto.Campinas/SP: Mercado das Letras; São Paulo: Educ, 2002.

MARQUES NETO, Agostinho Ramalho. A ciência do Direito: conceito, objeto, método. Rio de Janeiro: Renovar, 2001.

MINAYO, Maria Cecília de Sousa. (Org.). Pesquisa social: Teoria, método e criatividade. Petrópolis: Vozes, 2016.

OLIVEIRA, Isabelle. A metáfora dentro do universo do discurso jurídico. Estudos Linguísticos, São Paulo, 43 (3), p. 1157-1165, set./dez. 2014.

PARINI, Pedro. A noção de direito entre conceito e metáfora. Prim@ Facie, v. 13, n. 24, p. 01-37, 2014.

PARINI, Pedro. A retórica da metáfora dos modelos na teoria do direito. Sequência, n. 67, p. 81-110, dez. 2013.

PARINI, Pedro. O discurso metafórico e a construção retórica de verdades no direito. R. Dir. Gar. Fund., v. 16, n. 1, p. 11-46, jan/jun 2015.

PELOSI, Ana Cristina; FELTES, Heloísa Pedroso de Moraes; FARIAS, Emília Maria Peixoto (orgs.). Cognição e linguística: explorando territórios, mapeamentos e percursos. Caxias do Sul/RS: Educs, 2014.

SCHMITTE, Rodolf. Análise sistemática de metáforas: um método de pesquisa qualitativa. Tradução: Adriano Dias de Andrade. Recife: Ed. UFPE, 2017.

SOUSA, Fernanda Cunha. O que é a linguística cognitiva?. Revista Entretextos, vol. 7, n. 1, p. 4-21, jan/dez. 2007.

VEREZA, Solange Coelho. Literalmente falando: sentido literal e metáfora na metalinguagem. Niterói: EdUFF, 2007. 